Бабаліч В.А., Маленюк Т.В. Центральноукраїнський державний педагогічний університет імені Володимира Винниченко

\title{
ТЕНДЕНЦІЇ ТА ПЕРСПЕКТИВИ ВИКЛАДАННЯ ДИСЦИПЛІНИ «НАДАННЯ ПЕРШОЇ ДОЛІКАРСЬКОЇ ДОПОМОГИ У ПРОЦЕСІ ЗАНЯТЬ ФІЗИЧНОЮ КУЛЬТУРОЮ І СПОРТОМ" ДЛЯ СТУДЕНТІВ ТА СЛУХАЧІВ КУРСІВ ПІДВИЩЕННЯ КВАЛІФІКАЦІЇ У ЗАКЛАДАХ ВИЩОЇ ОСВІТИ
}

\begin{abstract}
Анотація. Стаття присвячена вивченню тенденцій та перспектив викладання дисципліни «Надання першої долікарської допомоги у процесі занять фрізичною культурою і спортом» для студентів та слухачів курсів підвищення кваліфікації у закладах вищої освіти з урахуванням очно-дистанційної форми навчання за для підвищення якості їі викладання. В статті представлено структуру та змістове наповнення курсу, яке виконано з врахуванням вимог до здійснення невідкладних дій, спрямованих на врятування та збереження життя людини та порядку надання домедичної допомоги особам при невідкладних станах не медичними працівниками. Запропоновано під час опрацювання практичних начинок запровадити кейсметод. При реалізації методу встановлено, що студенти краще навчилися переносити теоретичні знання на практику, пращювати в команді, приймати спільні рішення, розвинули навички аналізувати та мислити критично, все це сприяе кращій комунікащії і допомагає швидко в критичних ситуащіях приймати спільні, правильні рішення. Кейс-метод наблизив процес навчання до реальних ситуацій, які можуть трапитись під час навчально-тренувального процесу у професійній діяльності, таким чином відбувається формування життевих і профресійних компетентностей.
\end{abstract}

Ключові слова: дисципліна «Надання першої долікарської допомоги у процесі занять фрізичною культурою і спортом», структура і зміст, кейс-метод, студенти, слухачі курсів підвищення кваліфрікації.

Babalich Viktoria, Maleniuk Tetyana

Volodymyr Vynnychenko Central Ukrainian State Pedagogical University

\section{TRENDS AND PROSPECTS OF DISCIPLINE TEACHING "PROVISION OF FIRST MEDICAL ASSISTANCE IN THE PROCESS PHYSICAL CULTURE AND SPORTS ACTIVITIES" FOR STUDENTS AND LISTENERS OF QUALIFICATION COURSES IN INSTITUTIONS HIGHER EDUCATION}

Summary. The article is devoted to the study of trends and prospects of teaching the discipline "Provision of first medical assistance in the process physical culture and sports activities" for students and listeners of advanced training courses in higher education to improve the quality of its teaching and taking into account distance learning. The purpose of the article - based on the study of existing trends to justify the prospects and content of the discipline "First aid in the process of physical culture and sports" and to introduce a case method to im-prove the quality of its teaching. The article presents the structure and content of the course, which is performed taking into account the requirements for emergency actions aimed at saving and listeners lives and the procedure for providing home care to persons in emergencies by non-medical workers. It is proposed to introduce a case method during the processing of practical fillings. In practical classes, students and listeners for each topic prepared a set of situational tasks with different levels of complexity. The implementation of the method will take place in three stages. At each stage, the levels of difficulty are determined using three types of cases: case study - a task within one topic; case exercise - when you need not only to establish the order of the correct actions for the implementation of first aid, but also to reproduce a certain skill; case situation - involves solving a set of measures, situation analysis, organization of pre-medical care by several people. During the implementation of the method it was found that students better learn to transfer theoretical knowledge into practice, work in a team, make joint decisions, develop skills to analyze and think critically, all this contributes to better communication and helps to quickly make joint, correct decisions. The case method brought the learning process closer to real situations that may occur during the educational and training process in professional activities, thus the formation of life and professional competencies.

Keywords: discipline "Provision of first medical assistance in the process physical culture and sports activities", structure and content, case method, students, listeners of advanced training courses.

Постановка проблеми. Нещодавно затверджено і введено в дію стандарт вищої освіти України для першого бакалаврського рівня вищої освіти за спеціальністю 017 фізична культура і спорт [7], згодом розроблено стандарт для другого магістерського рівня [8]. В яких визначено перелік загальних, спеціальних компетентностей випускника. Хочемо зосередити увагу на деяких з них, а саме: здатність до адаптації та дії в новій ситуації; здатність ставити та вирішувати проблеми; здатність надавати долікарську допомогу під час виникнення невідкладний станів. Відповідно серед результатів навчання визначено вміння надавати долікарську допомогу при невідкладних станах та патологічних процесах в організмі людини. Введення зазначених компетентностей зумовило перегляд підходів до формування компонентів освітньої програми. Таким чином впроваджено в освітню програму спеціальності 017 Фізична культура і спорт обов'язковий 
компонент «Надання першої долікарської допомоги у процесі занять фрізичною культурою і спортом». Зумовлено це необхідністю тренерів у разі нещасних випадків під час тренувань володіти знаннями і практичними навичками надання долікарської допомоги [2]. 3 таких самих міркувань та 3 метою оновлення й вдосконалення практичних навиків дана дисципліна введена в освітню програму для слухачів курсів підвищення кваліфрікації тренерів та фрахівців у сорері фрізичної культури і спорту [4].

Аналіз останніх досліджень і публікацій. Для того щоб у студентів, тренерів під час вивчення дисципліни сформувались необхідні компетентності важливо зосередити увагу на едективних, перевірених часом, сучасних технологіях і методах, що в умовах очно-дистанційного навчання, сприятимуть засвоєнню практичних навиків. Досвід викладачів-науковців, що викладають клінічні дисципліни [5; 6] переконуе, що одним 3 таких інноваційних підходів $\epsilon$ кейс-метод. Відомо, що вперше цей метод апробовано у Гарвардській школі права (1879р.), не дивлячись на те, що ідея не нова, однак до сьогодні він вважаеться едективним способом засвоєння практичних навичок, особливо при вивченні медичних дисциплін.

Науковці вважать [1;9], що специфрікою медичних кейсів $є$ те, що вони більше зосереджені на фрормуванні професійних компетентностей ніж отримані нових знань. Адже в тексті «кейсів» розглянута конкретна ситуація, яка потребує швидкого аналізу ситуації та прийняття рішень. Традиційно кейс-метод націлений на реалізацію певного алгоритму дій відповідно до умов ситуащії при цьому не існуе єдиного правильного рішення. Зважаючи на такі специфічні особливості реалізації даного методу вважаємо, що він буде ефрективним при викладанні зазначеної дисщипліни.

Виділення невирішених раніше частини загальної проблеми. В сьогоднішніх умовах очно-дистанційної форми навчання виникла необхідність розглянути тенденщії та перспективи викладання дисципліни «Надання першої долікарської допомоги у процесі занять фрізичною культурою і спортом».

Мета статті - на основі вивчення існуючих освітніх тенденщій обгрунтувати перспективи i змістове наповнення дисципліни «Надання першої долікарської допомоги у процесі занять фрізичною культурою і спортом» та запровадити кейс-метод для підвищення якості її викладання.

Виклад основного матеріалу дослідження. У процесі аналізу законодавчої бази, за обраною темою дослідження, навчально-методичної документащії, з'ясовано, що структура та зміст дисципліни «Надання першої долікарської допомоги у процесі занять фрізичною культурою і спортом» мають бути сформовані з урахуванням вимог до здійснення невідкладних дій, спрямованих на врятування та збереження життя людини у невідкладному стані. Обумовлено це тим, що на законодавчому рівні урегульовано порядок надання домедичної допомоги особам при невідкладних станах не медичними працівниками [3], яким ми будемо керуватись при структуруванні та змістовому наповненні курсу.
Також при формуванні тематики курсу потрібно враховувати характер нещасних випадків, які трапляються під час тренувань і змагань, а також те, що зазначені фрахівці не мають медичної освіти. Додатково для слухачів курсів підвищення кваліфрікації проведено вхідне тестуван-ня 3 метою виявлення рівня володіння знаннями і практичними навичками надання долікарської допомоги. 3 урахуванням зазначеного пропонується наступний алгоритм формування змістового наповнення дисципліни «Надання першої долікарської допомоги у процесі занять фрізичною культурою і спортом» (табл. 1).

Для ефективного засвоєння навчального матеріалу даної дисципліни пропонуемо використовувати кейс-метод. Тематика курсу анонсує ситуації, які можуть виникнути під час тренувань i змагань. Зазвичай травматизм у спорті та нещасні випадки мають ненавмисний та непередбачуваний характер. Відповідно діяти тренер у таких ситуація повинен швидко, відповідально, впевнено, спираючись на власний досвід за певним алгоритмом дій.

При реалізації даного кейс-методу ми будемо дотримуватись традиційних підходів. На практичних заняттях студентам і слухачам до кожної теми підготовлено комплекс ситуаційних завдань 3 різним рівнем складності та строками виконання. Так, на першому етапі підготовки під наглядом викладача студенти приймають участь в обговоренні ситуації, складають послідовність дій надання першої долікарської допомоги, демонструють практичні навички. На цьому етапі роль викладача зведена до мінімум він лише спостерігач і тільки в разі крайньої необхідності приеднуеться до обговорення.

Наступний етап, передбачає попередню підготовку. Для ознайомлення студентам надана самостійна робота у вигляді ситуаційних завдань (трьох типів) 3 подальшим обговоренням і демонстрацією практичних навичок в групі (аудиторне заняття).

Третій етап передбачає самостійну аудиторну роботу за наданими ситуаційними завданнями, та демонстрацією практичних навичок (час на підготовку обмежений). На заняттях студентам і слухачам ставились як індивідуальні так і групові (2-3 особи) завдання для вирішення проблемної ситуації, щодо організащії й проведення невідкладний дій.

На всіх етапах застосовано три типи кейсів:

1. Кейс випадок - завдання у межах одніеї теми. Наприклад, під час тренувань на стадіоні спортсмен впав, отримав травму коліна. Не може во-рухнутись і підвестись на ноги. Потрібно підготувати алгоритм дій надання першої долікарської допомоги.

2. Кейс вправа - коли потрібно не тільки встановити порядок правильних дій для здійснення першої долікарської допомоги, а також відтворити певну навичку. Наприклад, продемонструвати послідовність дій при зупинщі кровотечі, накласти пов'язку.

Орієнтовний зміст ситуаційної вправи. На тренуванні, при виконанні вправ на турніку спортсмен зірвався униз головою з висоти двох метрів. Спортсмен після падіння у свідомості, скаржиться на головний біль та біль у шийному відділені хребта. На руці рана 3 якої тече кров. 
Таблиця 1

Структура та змістове наповнення курсу «Надання першої долікарської допомоги у процесі занять фізичною культурою і спортом»

\begin{tabular}{|c|c|c|c|c|}
\hline \multirow[b]{2}{*}{ № } & \multirow[b]{2}{*}{ Тематика курсу } & \multirow[b]{2}{*}{ Змістове наповнення } & \multicolumn{2}{|c|}{ Кількість годин } \\
\hline & & & $\begin{array}{c}\text { Перший } \\
\text { (бакалаврський) } \\
\text { рівень освіти }\end{array}$ & $\begin{array}{c}\text { Слухачі } \\
\text { курсів } \\
\text { підвищення } \\
\text { кваліфікації }\end{array}$ \\
\hline 1 & 2 & 3 & 4 & 5 \\
\hline 1 & $\begin{array}{l}\text { Організаційно- } \\
\text { правовий аспект } \\
\text { першої долікарської } \\
\text { допомоги. }\end{array}$ & $\begin{array}{l}\text { 1. Загальні правила і підходи до надання ПДД } \\
\text { (далі - ПДД). } \\
\text { 2. Нормативно-правове забезпечення надання } \\
\text { ПДД. }\end{array}$ & 2 & \multirow{3}{*}{1} \\
\hline 2 & $\begin{array}{l}\text { Загальні основи } \\
\text { надання ПДД. }\end{array}$ & $\begin{array}{l}\text { 1. Принципи надання ПДД. } \\
\text { 2. Алгоритм надання ПДД. } \\
\text { 3. Засоби ПДД. } \\
\text { 4. Аптечка тренера ПдД. } \\
\text { 5. Ознаки життя і смерті. }\end{array}$ & 2 & \\
\hline 3 & $\begin{array}{l}\text { Транспортування } \\
\text { постраждалих. } \\
\text { Основи десмургії. }\end{array}$ & $\begin{array}{l}\text { 1. Транспортування постраждалих, положення } \\
\text { постраждалого при транспортуванні. } \\
\text { 2. Методика накладання пов'язок. }\end{array}$ & 6 & \\
\hline 4 & $\begin{array}{l}\text { ПДД при травмах } \\
\text { опорно-рухового } \\
\text { апарату. }\end{array}$ & $\begin{array}{l}\text { 1. Різновиди травм опорно-рухового апарату. } \\
\text { 2. Правила іммобілізації. } \\
\text { 3. ПДД при підозрі на пошкодження хребта. } \\
\text { 4. ПДД при підозрі на травму голови (черепно- } \\
\text { мозкова травма), струс мозку. } \\
\text { 5. ПДД при підозрі на травму грудної клітини. } \\
\text { 6. ПДД при підозрі на перелом кісток кінцівок. } \\
\text { 7. ПДД постраждалим при падінні з висоти. }\end{array}$ & 8 & 1 \\
\hline 5 & $\begin{array}{l}\text { ПДД при ранах, } \\
\text { кровотечах та шоці. }\end{array}$ & $\begin{array}{l}\text { 1. Класифікація ран та види кровотеч. } \\
\text { 2. ПДД при кровотечах (артеріальна, венозна, } \\
\text { внутрішня, кровотеча з органів черевної } \\
\text { порожнини, проникаючи поранення грудної } \\
\text { клітки, носова кровотеча). } \\
\text { 3. ПДД при рані кінцівки, в тому числі } \\
\text { ускладненою кровотечою. } \\
\text { 4. ПДД при травмі ока, вуха. } \\
\text { 5. ПДД при шоці. }\end{array}$ & 8 & 1 \\
\hline 6 & $\begin{array}{l}\text { ПдД при } \\
\text { невідкладних } \\
\text { серцево-судинних } \\
\text { станах. }\end{array}$ & $\begin{array}{l}\text { 1. ПДД при серцевому нападі. } \\
\text { 2. ПДД при раптовій зупинці серця. } \\
\text { 3. Порядок проведення серцево-легеневої } \\
\text { реанімації. } \\
\text { 4. ПДД при гіпертонічному кризі. } \\
\text { 5. ПДД при інсульті. }\end{array}$ & 8 & 1 \\
\hline 7 & $\begin{array}{l}\text { ПДД при опіках, } \\
\text { переохолоджені, } \\
\text { перегріванні. }\end{array}$ & $\begin{array}{l}\text { 1. ПДД постраждалим з опіками (термічні, } \\
\text { хімічні). } \\
\text { 2. ПДД постраждалим з } \\
\text { переохолодженнями /відмороженням. } \\
\text { 3. ПДД постраждалим при перегріванні } \\
\text { (тепловий, сонячний удари). }\end{array}$ & 6 & 1 \\
\hline 8 & $\begin{array}{l}\text { ПДД } \\
\text { при порушенні } \\
\text { функції дихання. }\end{array}$ & $\begin{array}{l}\text { 1. Методика штучної вентилящії легень. } \\
\text { 2. ПДД постраждалим при порушені } \\
\text { прохідності дихальних шляхів. } \\
\text { 3. ПДД при задусі. }\end{array}$ & 6 & \multirow[b]{3}{*}{1} \\
\hline 9 & $\begin{array}{l}\text { ПДД при утоплені } \\
\text { та удушені. }\end{array}$ & $\begin{array}{l}\text { 1. ПДД постраждалим без свідомості. } \\
\text { 2. ПДД при утоплені. } \\
\text { 3. ПДД при удушені. }\end{array}$ & 6 & \\
\hline 10 & $\begin{array}{l}\text { ПДД при інших } \\
\text { невідкладних } \\
\text { станах різного } \\
\text { походження. }\end{array}$ & $\begin{array}{l}\text { 1. ПДД при укусах тварин та комах. } \\
\text { 2. ПДД при судомах (епілепсії). } \\
\text { 3. ПДД при діабеті. } \\
\text { 4. ПДД при отруєнні (гостре отруєння } \\
\text { невідомою речовиною, передозування } \\
\text { опіоїдами). } \\
\text { 5. ПДД при діареї, закрепі. } \\
\text { 5. ПДД при ураженні електричним струмом та } \\
\text { блискавкою. }\end{array}$ & 8 & \\
\hline & & Разом: & 60 & 6 \\
\hline
\end{tabular}


Потрібно підготувати алгоритм дій надання першої долікарської допомоги. Продемонструвати практичні навички.

3. Кейс ситуація - передбачає вирішення комплексу заходів, аналіз ситуації, організацію долікарської допомоги декількома особами. Наприклад, зупинка кровотечі, іммобілізація та транспортування потерпілого.

Орієнтовний зміст кейс-ситуащії. Під час велотренувань на шосе сталося ДТП. Водій легкового автомобіля скоїв наїзд на велосипедиста. Внаслідок зіткнення у спортсмена забій м'яких тканин тулуба, відкритий перлом ноги. Потрібно організувати першу допомогу на місці з подальшим транспортуванням потерпілого. Необхідно врахувати, що на місці аварії присутні спортсмени команди.

За нашими спостереженнями, при реалізації цього методу встановлено, що студенти краще навчилися переносити теоретичні знання на практику, працювати в команді, приймати спільні рішення, розвинули навички аналізувати та мислити критично все це сприяе кращій комунікацї і допомагає швидко в критичних ситуаціях приймати спільні, правильні рішення. Кейс-метод наблизив процес навчання до реаль- них ситуащій, які можуть трапитись під час навчально-тренувального процесу у професійній діяльності, таким чином відбувається формування життєвих і профресійних компетентностей.

Висновки 3 даного дослідження i перспективи:

1. Під час вивчення тенденцій та перспектив викладання дисципліни «Надання першої долікарської допомоги у процесі занять фізичною культурою і спортом» з'ясовано, що структура та зміст мають бути сорормовані з урахуванням встановлених вимог щодо надання домедичної допомоги особам при невідкладних станах.

2. Запропоновано структуру та змістове наповнення дисципліни «Надання першої долікарської допомоги у процесі занять фрізичною культурою і спортом».

3. Для забезпечення якості викладання практичної дисципліни в умовах очно-дистанщійного навчання запропоновано інноваційні підходи, а саме використання кейс-методу.

4. Представлено методику впровадження кейсметоду, як перспективний напрям формування фрахових компетентностей під час вивчення дисципліни, яка потребуе подальшого удосконалення.

\section{Список літератури:}

1. Андрущак Т.Г. Особливості організації процесу фахової підготовки на основі кейс-методу. Черкаси, 2015. C. 218-222.

2. Наказ Міністерства молоді та спорту України від 28.10.2016 № 4080 «Про затвердження Довідника кваліфікаційних характеристик професій працівників». Випуск 85 «Спортивна діяльність». URL: https://zakon.rada.gov.ua/rada/show/v4080728-16\#n12 (дата звернення: 02.11.2021).

3. Наказ Міністерства охорони здоров’я України від 16.06.2014 № 398 «Про затвердження порядків надання до медичної допомоги особам при невідкладних станах». URL: https://zakon.rada.gov.ua/laws/show/z075014\#Text (дата звернення: 02.11.2021).

4. Постанова Кабінету міністрів України від 21. 11. 2012 № 115 «Порядок підготовки та підвищення кваліфрікації осіб, які зобов'язані надавати домедичну допомогу». URL: https://zakon.rada.gov.ua/laws/show/1115-2012\%D0\%BF\#n8 (дата звернення: 02.11.2021).

5. Путинцев А.Н., Алексеев Т.В. Кейс-метод в медицинском образовании: современные программные продукты. Международный журнал прикладных и фбундаментальных исследований. 2016. № 12-9. С. 1655-1659.

6. Січкоріз O.Є., Іванюшко О.В., Павленко I.А. Впровадження кейс-методу при викладанні теми «Коми при цукровому діабеті» лікарям-інтернам зі спеціальності «Анестезіологія». Медична освіта. Тернопіль, 2018. № 3. C. 70-73.

7. Стандарт вищої освіти: другий (магістерський) рівень вищої освіти, галузь знань 01 Освіта / Педагогіка, спеціальність 017 Фізична культура і спорт. Затверджений Наказом Міністерства освіти і науки України від 11 травня 2021 року № 516. 11 с.

8. Стандарт фахової передвищої освіти України: фаховий молодший бакалавр, галузь знань 01 Освіта / Педагогіка, спеціальність 017 Фізична культура і спорт. Затверджений Наказом Міністерства освіти і науки України від 24 квітня 2019 року № 567.11 с.

9. Філоненко М.М. Методика викладання у вищій медичній школі на засадах компетентнісного підходу. Київ : Центр учбової літератури, 2016. 88 с.

\section{References:}

1. Andrushhak T. Gh. (2015) Osoblyvosti orghanizaciji procesu fakhovoji pidgho-tovky na osnovi kejs-metodu [Features of the organization of the process of professional training on the basis of the case method]. Cherkasy, pp. 218-222. (in Ukrainian)

2. Nakaz Ministerstva molodi ta sportu Ukrajiny vid 28.10.2016 № 4080 «Pro zatverdzhennja Dovidnyka kvalifikacijnykh kharakterystyk profesij pracivnykiv, Vypusk 85 "Sportyvna dijaljnistj» ["On approval of the Handbook of qualification characteristics of occupations of workers, Issue 85" Sports activities"]. Available at: https://zakon.rada.gov.ua/rada/show/v4080728-16\#n12 (accessed 02 November 2021). (in Ukrainian)

3. Nakaz Ministerstva okhorony zdorov'ja Ukrajiny vid 16.06.2014 № 398 «Pro zatverdzhennja porjadkiv nadannja do medychnoji dopomoghy osobam pry nevidkladnykh stanakh» [«On approval of the procedures for providing medical care to persons with non-urgent conditions»]. Available at: https://zakon.rada.gov.ua/laws/show/z075014\#Text (accessed 02 November 2021). (in Ukrainian)

4. Postanova Kabinetu ministriv Ukrajiny vid 21.11.2012 № 115 «Porjadok pidghotovky ta pidvyshhennja kvalifikaciji osib, jaki zobov'jazani nadavaty domedychnu dopomoghu» [The procedure for training and retraining of persons who are obliged to provide home care]. Available at: https://zakon.rada.gov.ua/laws/show/1115-2012\%D0\%BF\#n8 (accessed 02 November 2021) (in Ukrainian)

5. Putyncev A. N., Alekseev T. V. (2016) Kejs-metod v medycynskom obrazovanyy: sovremennye proghrammnye produkty [Case method in medical education: modern software products.]. Mezhdunarodnyj zhurnal prykladnykh y fundamentaljnykh yssledovanyj, no. 12-9, pp. 1655-1659. (in Ukrainian) 
6. Sichkoriz O.Je., Ivanjushko O. V., Pavlenko I. A. (2018) Vprovadzhennja kejs-metodu pry vykladanni temy «Komy pry cukrovomu diabeti» likarjam-internam zi specialjnosti "Anesteziologhija» [Implementation of the case method for teaching the topic "Coma for diabetes" to doctors-interns in the specialty "Anesthesiology"]. Medychna osvita. Ternopilj, no. 3, pp. 70-73. (in Ukrainian)

7. Standart vyshhoji osvity: drughyj (maghistersjkyj) rivenj vyshhoji osvi-ty, ghaluzj znanj 01 Osvita / Pedaghoghika, specialjnistj 017 Fizychna kuljtura i sport [Standard of higher education: second (master's) level of higher education, field of knowledge 01 Education / Pedagogy, specialization 017 Physical culture and sports] Zatverdzhenyj Nakazom Ministerstva osvity i nauky Ukrajiny vid 11 travnja (2021) № 516, pp. 11. (in Ukrainian)

8. Standart fakhovoji peredvyshhoji osvity Ukrajiny: fakhovyj molodshyj bakalavr, ghaluzj znanj 01 Osvita / Pedaghoghika, specialjnistj 017 Fizychna kuljtura i sport [Standard of professional higher education of Ukraine: professional junior bachelor, field of knowledge 01 Education / Pedagogy, specialty 017 Physical culture and sports] (2019) Zatverdzhenyj Nakazom Ministerstva osvity i nauky Ukrajiny vid 24 kvitnja № 567, pp. 11. (in Ukrainian)

9. Filonenko M. M. (2016) Metodyka vykladannja u vyshhij medychnij shkoli na zasadakh kompetentnisnogho pidkhodu [Methods of teaching in higher medical school on the basis of the competence approach]. Kyiv: Centr uchbovoji literatury, pp. 88. (in Ukrainian) 